\title{
Obesity among females in Al-Sader city Baghdad, Iraq, 2017.
}

\author{
Hadeel M.Jasim* \\ Hassan M.Abdul Hussein** \\ Eman A. Al-Kaseer**
}

\author{
FABHS \\ FIBMS \\ FIBMS
}

\begin{abstract}
:
Background: obesity is a serious public health problem. Literatures in Iraq explained that obesity due to change in economy and Lifestyles.

JFac Med Baghdad

2018; Vol.60, No.2

Received: Nov., 2017

Accepted: Feb., 2018

Objective: To report on prevalence of obesity among women in Al- sader City, Baghdad. 2017.

Method: A total of 440 females were included in this study. They were Selected randomly from relatives to patients accompanied them In attending to primary health care centers. BMI (body mass index) to assess the Weight. Demo-graphic data were requested too.

Result: The prevalence of obesity was $35.2 \%$. Age , education, divorced Widows were determinants of obesity. Employment and crowding Index (socioeconomic status) were not obvious determinants of obesity.
\end{abstract}

Conclusion: High prevalence of obesity was observed.

Keywords: obesity, Al-sader city, Iraq.

\section{Introduction:}

Obesity is a serious public health problem. In Iraq, the prevalence of overweight and obesity were $61.1 \%$ and $76 \% 1,2$. These high figures were explained by Economic development, urbanization and improved living conditions have led to greater consumption of food and it was accompanied by sedentary life. The change in this situation led to obesity 3,4 . Al-Sader city is one of the most densely packed communities in the Middle East with low socioeconomic status5. Crowding index is a reflection to socioeconomic status6. Low quality diets (energy dense diets that are poor nutrient) consumed by persons of lower socioeconomic status7. This study was carried to estimate the prevalence of obesity among females in AL-Sader city during 2017.

\section{Materials \&Methods:}

Total 440 females aged, were included in the study. They were selected randomly from AL-Sader city for the period Augest-December/2016. They were apparently healthy attending Primary Health Care Center (PHCC), accompanied their children or relatives attending Antenatal Care (ANC) services in PHCC. Requested data including demographic data (age, education, marital status, occupation) and crowding index ${ }^{8}$. These high figures were explained by Excess of body fat was measured using Body Mass Index (BMI). It is calculated by weight in $(\mathrm{K}, \mathrm{g}$ ) divided by height in squared meters. The participant females were weighed using electronic scale, bare foot and dressed in lightest clothes as possible.

The height was measured by standard tape measure (cm) fixed to the wall. Variables were analyzed Using Chi-square test to examine the association

*Ministry of Health, Primary Health Care AL-Sader city.E-mail:mhadeel12@yahoo.com.

**Dept. of Community Medicine, College of Medicine.
Between dependent variable (obesity) and independent variables (age, marital status, education, and crowding index). $\mathrm{P}$ value $<0.05$ was considered significant.

\section{Results:}

High rates of overweight and obesity were noticed in $18(30.5 \%)$ and $9(15.3 \%)$, respectively, among those aged $\leq 20$ years. Among those aged $>20$ years, overweight was found in $134(35.2 \%)$ and obesity in $146(38.3 \%)$. Age was significantly associated with overweight and obesity $\left(\chi^{2}=21, \mathrm{df}=1, \mathrm{p}=0.001\right)$. Out of the single females, $12(27.3 \%)$ and $14(31.8 \%)$ were overweight and obese. Among the married women, $123(35.1 \%)$ and $117(33.4 \%)$ were overweight and obese. Overweight and obesity among divorced were found in $24(52.2 \%)$ for both. Marital status was significantly affect the weight of the women $\left(\chi^{2}=12.5, \quad \mathrm{df}=4, \quad \mathrm{p}=0.01\right)$. Out of illiterate women, $50(34.2 \%)$ and $57(39 \%)$ were overweight and obese, respectively. Overweight among those with primary and secondary education were $56(31.3 \%)$ and $29(43.3 \%)$, respectively, and the obesity were $73(40.6 \%)$ and 16 (23.9\%), respectively. There was significantly difference in weight between different educational levels $\left(\chi^{2}=14.3\right.$, $\mathrm{df}=6, \mathrm{p}=0.02)$. Overweight and obesity among housewives were 137 (35.3\%) and 144 (37.1\%) respectively. Among the employed women overweight and obesity were 13(39.4\%) and $8(42.1 \%)$. The working status was not associated with the weight $\left(\chi^{2}=2.6, \quad \mathrm{df}=4, \quad \mathrm{p}=0.6\right)$. In women living in houses with low crowding index $\leq 2$, the overweight and obesity were $19(32.2 \%)$ and 16 $(27.1 \%)$, respectively and in those living in houses with high crowding index $>2$, the overweight and obesity were $133(34.9 \%)$ and 139 (36.5\%). There was no significant differences in overweight and obesity in women and those lived in low and high crowding index $\left(\chi^{2}=3.8, \quad \mathrm{df}=2, \quad \mathrm{p}=0.1\right)$. 
Table 1: Sociodemograghic characteristics of studied group.

\begin{tabular}{llll}
\hline Variables & & $\mathrm{N}$ & $\%$ \\
\hline \multirow{2}{*}{ Age(years) } & $\geq 20$ & 59 & 13.4 \\
\cline { 2 - 4 } & $<20$ & 381 & 86.6 \\
\hline \multirow{3}{*}{ Education } & illiterate & 146 & 33.2 \\
\cline { 2 - 4 } & primary & 180 & 40.9 \\
\cline { 2 - 4 } & secondary & 67 & 15.2 \\
\cline { 2 - 4 } Marital status & university & 47 & 10.7 \\
\hline \multirow{3}{*}{ Occupation } & Single & 44 & 10 \\
\cline { 2 - 4 } & married & 350 & 79.5 \\
\cline { 2 - 4 } & Divorced\&widowed & 46 & 10.5 \\
\hline \multirow{2}{*}{ Crowding } & Housewife & 388 & 88.2 \\
\cline { 2 - 4 } & Employed & 33 & 7.5 \\
\cline { 2 - 4 } & Student & 59 & 4.3 \\
\cline { 2 - 4 } & $\leq 2$ & 381 & 86.6 \\
\hline
\end{tabular}

Table 2: The association between obesity of participants and variables.

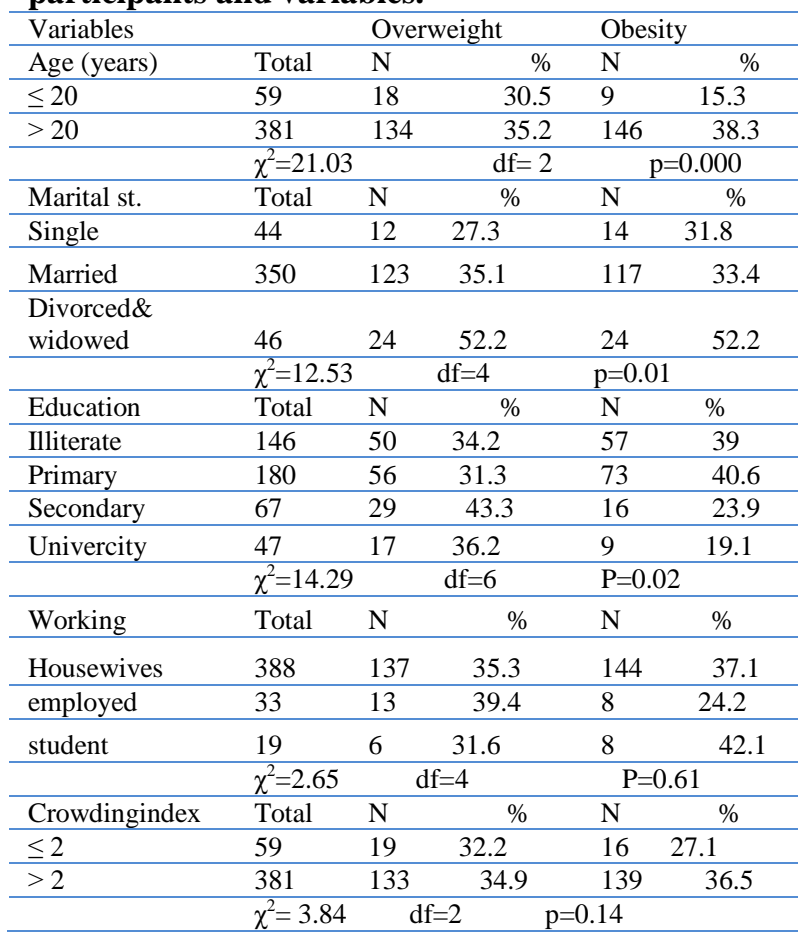

\section{Discussion:}

The prevalence of overweight and obesity were $34.5 \%$ and $35.2 \%$ respectively, both of them $69.7 \%$ ). Similar figure $(76 \%) 1$ was reported in Baghdad previously. Recently, high figure reported in southern Iraq (Hilla) $(80.5 \%)$ 9. The observed figure of overweight and obesity $(34.5 \%$ and $35.2 \%$, respectively) were almost similar to the reported national figures $(31.4 \%$ and $38.2 \%$, respectively). It was documented that the prevalence of overweight and obesity in Arabic countries were increased to alarming rates during the last decades 3 . Studies in East Mediterranean countries showed an alarming level among both children and adults11. World Health Organization warned the escalating epidemic of obesity could put the population in many countries at risk of developing non- communicable diseases (NCD) 12. The high prevalence of overweight and obesity in Iraq was explained by consumption of high caloric food, and social habits1. Recently, it was reported that the type of dressing affect the body weight of females by multiple mechanisms 13 . Consumption of high caloric diet in Iraq explained by the fact of economic improvement and redistribution of wealth after the last political events (i.e. change of regime). Festivals, gathering in restaurants might play a role in this phenomenon. High prevalence of overweight and obesity observed in this study might be attributed to nutritional transition. The last was described after demographic and epidemiologic transition16. It was documented that nutritional transition is striking to low income countries too. The study, revealed a significant association between age and obesity. This finding is consistent with other studies17, 18. The weight of married, divorced and widowed women were significantly higher than single females $(p=0.01)$. This finding might be explained by social norms. This finding is in the line of that Arabian countries17. Single females are more concern about their appearance (slim, nice looking.. etc)19-21. It was noticed that overweight and obesity were highly prevalent among lower educated women $(p=0.02)$. It is in line with that reported in Basrah (southern Iraq)2, Jordan22, and England23. But in contrast with that in African countries 24, 25. The difference might be attributed to the fact that the high educated women usually had jobs which in turn means high income, and using fast food which in turn enhance increasing body weight 26 . Sedentary life is another factor for increase in body weight among the high educational women27. In the line of that other studies28. Occupation was playing no role on overweight and obesity. This study showed that overweight and obesity were not affected by crowding index $(p=0.1)$. It is in contrast with that reported in other studies 29 . This finding might be attributed to the fact that majorty of the sample $(86.6 \%)$ ) were living in high crowded houses i.e. $>2$. It was mentioned that AL- Sader city is one of densely packed communities in the middle east5.

\section{Conclusion:}

High prevalence of overweight and obesity were noticed in AL-Sader city.

\section{Authors' Contributions:}

Hadeel M. Jasim: collection, analysis of data. Sharing in writing the Manuscript.

Hassan M. Abdul hussein: entering the data to the computer and editing Manuscript.

Eman A. Al- Kaseer: Suggesting the problem, design of the study, sharing the manuscript.

\section{References:}

1. Al-Tawil N. G, Abdulla M.M, Abdul Ameer A.J. Prevalence of and factors associated with overweight and obesity among a group of Iraqi women. East. Mediterr. J. 2007;13(2):420-429.

2. Mansour AA, AL-Maliky AA, Sailh M. Population Overweight and Obesity Trends of Eight years in Basrah, Iraq. Epidemiol an open access Journal.2012;(2):1-3.

3. Badran M, Laher I. Obesity in Arabic - Speaking Countries. J of obesity.2011. 
4. Yousif B. The economy of Iraq since 2003-a follow up. The Wasnton Institute.2012.

5. Carpenter AC. Community resilience to sectarian violence in Baghdad, Christie DJ(ed). Springer. New York 2011.

6. Melki S, Beydoun HA, Khogali M, Tamin H, Yunis KA. Household crowding index acorrelate of socioeconomic status and interpregnancy spacing in an urban setting. J Epidemiol Community Health 2004,58:476-480.

7. Darmon N, Drewnowski A. Does social class predict diet quality? 1,2,3. Am J Cli Nutr. 2008; 87(5): 1107-1117.

8. World Bank. Confronting Poverty in Iraq. Main findings. Washington. DC: World Bank. http:// documents. world bank/ curated/en/Confrontingpoverty-in-Iraq-main-findings.

9. Yasir AA, AL-Amean ZK. Obese and overweight women and public Health Issue in Hilla City, Iraq. Int J Med Health, Biomedical Bioenineering pharm Engin 2016;10(3):164-169.

10. Iraq Ministry of Health. Chronic non communicable diseases risk factors survey in Iraq 2006. A step wise approach. Available at htt://www.fineprint.com Accessed at20/1/2007.

11. Sibia AM, Nasreddin L, Mokdad AH, Tabet M, Hwalla N. Nutrition Transition and cardiovascular Disease Risk factors in Middle East and North Africa Countries: Reviewing The Evidence. Ann Nutr Metab 2010;57:193-203.

12. Musaiger AO. Overweight and Obesity in Eastern Meditarranean Region: prevalence and possible causes. J obes 2011;(6):407237.

13. Farouk AA. Obesity Among Female students in Thiqar Univesity. Athesis submitted to Iraqi Board for Medical Specialization as partial fulfillment of the requirements for the Degree of Iraqi Board in Family Medicine.2015.

14. Yousif B. Economic Restructuring in Iraq: Intended and Unintended consequences. IJEI.2007;(41):43-60.

15. IRIN/Iraq 10 years an :Economy grows, but how many benefit?
www.irinnews.org/feature/2013/04/23/Iraq-10-yearsfrogotten-displacement-crisis.

16. Popkin BM, Adian LS, Ng SW. Now and then: The Global Nutrition Transtion: The pandemic of obesity in Developing Countries. Nutr Rev. 2012; 70(1):3-21. 17. Fouad MF, Rastem S, Ward KD, Maziak W. Prevalence of obesity and its associated factors in Aleppo. Syria. Prev. control 2006, 2(2):85-94.

18. Villareal DT, Apovian CM, Kushner RF, Klien S. Obesity in older adults. Technical review and position statement of the American Society for Nutrition and NAASO, The obesity society 1,2,3,4,5. Am J clin Nutr.2005;85:923-34.

19. Al-malki JS, AL-Jaser MH, Warsy AS. Overweight and obesity in Saudi females of child bearing age. International Journal of Obesity 2003;27:134-139.

20. Oxfam international, In Her Words: Iraqi women talk about their greatest concern and challenges. 2009. https://www.oxfam.org. (accessed 2 February 2017).

21. Ajlouni $K$, Jaddou H, Batiecha A. Obesity in Jordan. Int J Obes Relat Metab Dsord 1998;22:624628.

22. Ajlouni K, Jaddou H, Batiecha A. Obesity in Jourdan. Int $J$ Obes Relat Metab Disord 1998;22:624-628.

23. Popkin BM, Gordan -Larsen P. The nutrition transition: Worldwide obesity dynamics and their determinants. Int J Obes Metab Disord 2004; $28, S_{2} \_S_{9}$.

24. Gabary AR, Kpozehouen A, Houehanou YC, Djrolo F, Amoussou. MPG, Tchabi X, et al. Prevalence and risk factors of overweight and obesity: findings from a cross- sectional community based Survey in Benine, Glob Epidemiol Obes. 2014; 2(3):2-8.

25. Okoh M. Socio-Demograghic Correlates of overweight and obesity among women of Reproductive Age in Nigeria: African Jof Reproductive Health 2013; 17(4)66.

26. Mandal A. Obesity and Fast food. Life Science 2014. www.news- medical. Net/ health/ obesity_fast_food. (accessed 7January2017). 